\title{
RANCANG BANGUN VIRTUAL TOUR REALITY SEBAGAI MEDIA PROMOSI PARIWISATA DI PROPINSI RIAU
}

\author{
Yulia Fatma $^{1)}$, Regiolina Hayami ${ }^{2)}$, Arif Budiman ${ }^{3)}$, Yoze Rizki ${ }^{4)}$ \\ ${ }^{1234}$ Teknik Informatika, Fakultas Ilmu Komputer, Universitas Muhammadiyah Riau \\ 1yuliafatma@umri.ac.id, ${ }^{2}$ regiolinahayami@umri.ac.id, ${ }^{3}$ abud2294@gmail.com, ${ }^{4}$ yozerizki@umri.ac.id
}

\begin{abstract}
Riau has many new tourist attractions that are no less attractive to tourist attractions that are already well-known in other regions of Indonesia, but are not widely known by domestic and foreign tourists. So far, the promotion of tourist attractions is only based on writing and photos of one side that is less interactive. Increasing the promotion of tourism locations is needed to increase the interest of tourists to visit the place. One effort that can be done in the development of media promotion of tourist attractions is to use current technological developments, such as a Virtual Tour application. Virtual Reality (VR) application which is designed to be used as a medium of information and tourism promotion in Riau province. The impression of a virtual reality tour using $360^{\circ}$ degree photos makes users feel as if they are in the environment. The research method used is the ADDIE development model which consists of five stages which include analysis, design, development, implementation and evaluation. The sample data was used as many as 18 tourism sites taken from 3 districts namely Pekanbaru City, Kampar and Rokan Hulu. Based on the results of the study obtained all the functions of the application run well and are expected to help tourists and the public provide information about the location of tourist attractions and can increase the potential of tourism in the province of Riau, especially Pekanbaru City.
\end{abstract}

Keywords: virtual reality tour, promotion, tourism, riau, android

\begin{abstract}
Abstrak
Riau memiliki banyak tempat - tempat wisata baru yang tidak kalah menariknya dengan tempat wisata yang sudah terkenal di daerah lainnya di Indonesia, tetapi belum banyak diketahui oleh wisatawan domestik maupun mancanegara. Selama ini promosi tempat wisata hanya berdasarkan tulisan dan foto satu sisi yang kurang interaktif. Meningkatkan promosi lokasi pariwisata diperlukan untuk meningkatkan minat wisatawan untuk berkunjung ke tempat tersebut. Salah satu upaya yang dapat dilakukan dalam pengembangan media promosi tempat wisata adalah dengan menggunakan perkembangan teknologi saat ini, seperti sebuah aplikasi Virtual Tour. Aplikasi Virtual Reality (VR) yang dirancang digunakan sebagai media informasi dan promosi pariwisata provinsi Riau. Kesan virtual tour reality menggunakan foto $360^{\circ}$ derajat membuat pengguna dapat merasa seolah-olah berada di dalam lingkungan tersebut. Metode penelitian yang digunakan adalah Model pengembangan ADDIE yang terdiri dari lima tahapan yang meliputi analisis, desain, pengembangan, implementasi dan evaluasi. Data sampel digunakan sebanyak 18 tempat pariwisata yang diambil dari 3 kabupaten yaitu Kota Pekanbaru, Kampar dan Rokan Hulu. Berdasarkan hasil penelitian didapat semua fungsi aplikasi berjalan dengan baik dan diharapkan dapat membantu wisatawan serta masyarakat memberikan informasi tentang lokasi tempat wisata dan dapat meningkatkan potensi pariwisata di propinsi Riau khususnya Kota Pekanbaru.
\end{abstract}

Kata kunci: virtual tour reality, promosi, pariwisata, riau, android.

\section{PENDAHULUAN}

Pembangunan kepariwisataan di Provinsi Riau merupakan bagian integral dengan pembangunan daerah serta merupakan bagian yang tak terpisahkan dengan pembangunan kepariwisataan Nasional. Sumber-sumber potensi kepariwisataan baik berupa Objek dan daya tarik wisata, kekayaan budaya, alam dan lainnya, sumber daya manusia, serta usaha jasa pariwisata merupakan modal dasar bagi pembangunaan kepariwisataan daerah. Berdasarkan data yang dirangkum oleh Puslitbang Kementerian Pariwisata Republik Indonesia, jumlah pertumbuhan kunjungan wisatawan mancanegara yang masuk Bandara Internasional Sultan Syarif Kasim II Pekanbaru 
adalah sebanyak 40,2\%. Jumlah pertumbuhan kunjungan ini menempatkan Provinsi Riau pada posisi kedua nasional [1].

Riau memiliki banyak tempat - tempat wisata baru yang tidak kalah menariknya dengan tempat wisata yang sudah terkenal di daerah lainnya di Indonesia, tetapi belum banyak diketahui oleh wisatawan domestik maupun mancanegara. Selama ini promosi tempat wisata hanya berdasarkan tulisan dan foto satu sisi yang kurang interaktif. Meningkatkan promosi lokasi pariwisata diperlukan untuk meningkatkan minat wisatawan untuk berkunjung ke tempat tersebut [2]. Wisatawan domestik maupun mancanegara akan sangat tertarik jika mereka mempunyai bayangan suasana atau pemandangan disekeliling lokasi pariwisata tujuan. Salah satu upaya yang dapat dilakukan dalam pengembangan media promosi tempat wisata adalah dengan menggunakan perkembangan teknologi saat ini, seperti sebuah aplikasi Virtual Tour. Virtual Tour merupakan teknologi yang menempatkan user di dalam gambar dan memungkinkan user untuk meningkatkan kesadaran situasional serta meningkatkan daya lihat, tangkap dan menganalisa data virtual secara signifikan [3]. Virtual Tour dapat menampilkan secara virtual pemandangan di suatu tempat. Teknologi Virtual Tour yang sudah ada yaitu dengan gambar panorama $360^{\circ}$, dimana dengan teknologi ini suatu lokasi dapat direpresentasikan dalam gambar panorama $360^{\circ}$ yang dapat memberikan kesan seperti seolah-olah berada di tengah tengah lokasi tersebut.

Penelitian terkait virtual tour [4] menjelaskan adanya peningkatan ketertarikan lebih dari $50 \%$ pada setiap kriteria pengujian dari koresponden dengan penggunaan virtual tour sebagai media promosi. Penelitian lain yang juga menerapkan virtual tour menyatakan bahwa dihasilkan suatu sosialisasi atau pengenalan potensi wisata baru yang lebih menarik dalam menyampaikan informasi tentang tempat wisata baru di wilayah tersebut [5]. Penelitian ini bertujuan untuk menerapkan teknologi Virtual Reality (VR) sebagai media promosi pariwisata propinsi Riau.

\section{METODOLOGI PENELITIAN}

Tahapan dalam melakukan penelitian ini disusunlah sebuah kerangka penelitian atau langkah kerja agar penelitian ini sesuai dengan permasalahan yang akan dibahas. Adapun bentuk metode penelitan dapat dilihat pada Gambar 1 .

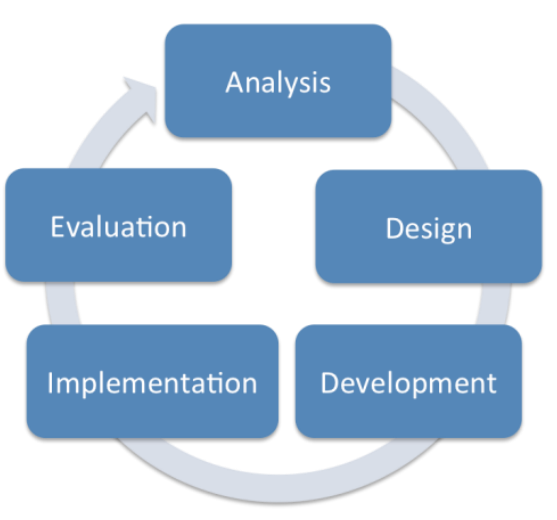

Gambar 1. Metode Penelitian

Metode penelitian yang digunakan adalah Model pengembangan ADDIE yang terdiri dari lima tahapan yang meliputi analisis (analysis), desain (design), pengembangan (development), implementasi (implementation) dan evaluasi (evaluation). Model ini memiliki beberapa tahapan yang sesuai dengan namanya yaitu (1) Analisis, (2) Desain, (3) Pengembangan, (4) Implementasi dan diakhiri dengan tahap (5) Evaluasi, namun model ADDIE memiliki fokus atau penekanan pada iterasi dan refleksi. Sehingga perbaikan secara terus menerus dapat dilakukan yang berfokus dari umpan balik[6][7]. Tahapan awal yang dilakukan sebelum melakukan pemodelan sistem adalah melakukan analisis kebutuhan sistem yang terdiri dari perangkat keras (hardware), perangkat lunak (software) maupun kebutuhan data. Selanjutnya yaitu tahap perancangan sistem menggunakan UML dan perancangan struktur menu. Tahapan selanjutnya adalah pengembangan yaitu mewujudkan rancangan menggunakan bahasa pemrograman C\# (C Sharp). Implementasi sistem dilakukan dengan merapkan sistem dan melakukan pengujian dengan metode black box testing. Hasil implementasi akan dievaluasi sesuai dengan ketidaksesuaian temuan pada saat pengujian hingga tujuan akhir tercapai.

Perangkat keras yang digunakan untuk membangun aplikasi Virtual Tour Reality tempat Pariwisata di Propinsi Riau ini menggunakan spesifikasi sebagai berikut:

a. Processor Intel ${ }^{\circledR}$ Core $^{\mathrm{TM}} \mathrm{i} 3-4210 \mathrm{U}$

b. Hard Disk berkapasitas $500 \mathrm{~GB}$.

c. Memory berkapasitas 2 - 4 GB.

d. LCD 15 inch serta Keyboard dan Mouse.

e. Smartphone Android yang dilengkapi dengan sensor gyro. 
Spesifikasi perangkat lunak yang dibutuhkan dalam penelitian ini adalah sebagai berikut:
a. Sistem Operasi Windows 10
b. Adobe Photoshop CS 3
c. Unity 2018.3.12
d. Google Camera
e. Google Cardboard

Pengumpulan data dilakukan dengan survei langung ke lokasi dan melakukan pengambilan foto $360^{\circ}$ menggunakan mode photo sphere pada aplikasi Google Camera. Foto $360^{\circ}$ adalah gambar panorama yang dapat diambil dari beberapa perangkat Android. Sistem operasi Android yang mulai mendukung photo sphere yaitu di Android 4.2 Jelly Bean, dan Nexus 4. Untuk dapat menggunakan fasilitas ini perangkat harus memiliki sensor Accelorometer dan Gyroscope agar dapat berfungsi [8]. Data yang digunakan terdiri dari nama tempat pariwisata, kabupaten, kategori. Data yang digunakan dalam penelitian ini berjumlah 18 data tempat pariwisata diantaranya dapat dilihat pada Tabel 1 .

Tabel 1. Foto $360^{\circ}$ Tempat Pariwisata

\begin{tabular}{|c|l|l|}
\hline No & Nama & \multicolumn{1}{|c|}{ Foto 360 $^{\circ}$} \\
\hline 1 & Danau buatan & Masjid An-Nur \\
\hline 2 & Pekanbaru & \\
\hline 3 & Masjid Raya & \\
\hline 4 & Pasar Bawah & \\
\hline
\end{tabular}

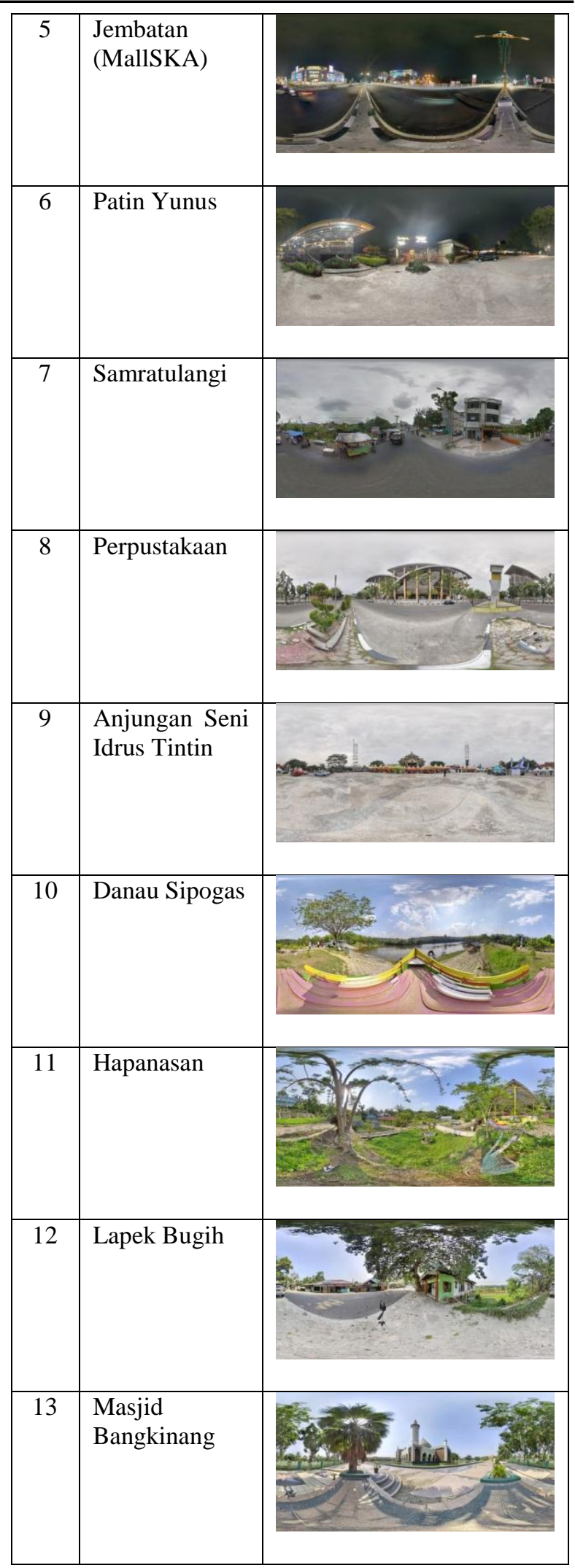




\begin{tabular}{|c|c|c|}
\hline 14 & $\begin{array}{l}\text { Masjid Pasir } \\
\text { Pangaraian }\end{array}$ & 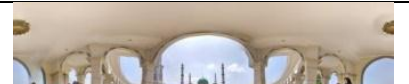 \\
\hline 15 & Nadin & \\
\hline 16 & $\begin{array}{l}\text { Rumah } \\
\text { Lontiok }\end{array}$ & \\
\hline 17 & $\begin{array}{l}\text { Rumah } \\
\text { Singgah Sultan } \\
\text { Siak }\end{array}$ & $y^{2}+a$ \\
\hline 18 & Sungai Hijau & 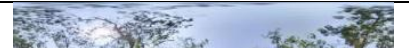 \\
\hline
\end{tabular}

\section{a. Use Case Diagram}

Use case diagram merupakan gambaran graphical dari aktor, dimana pada use case diagram menggambarkan manajemen sistem secara keseluruhan. Use case diagram digunakan untuk memodelkan abstraksi dan interaksi antara sistem dengan pengguna. Use case diagram sistem yang akan dibangun dapat dilihat pada Gambar 2.

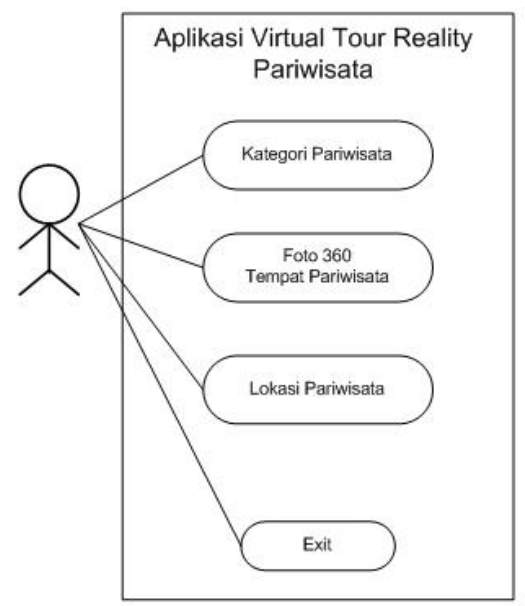

Gambar 2. Use Case Diagram
Deskripsi use case diagram pada Gambar 2 dapat dilihat pada Tabel 2 berikut.

Tabel 2. Deskripsi Use Case Diagram

\begin{tabular}{|c|l|l|}
\hline No. & \multicolumn{1}{|c|}{ Use Case } & \multicolumn{1}{|c|}{ Deskripsi } \\
\hline 1 & $\begin{array}{l}\text { Kategori } \\
\text { Pariwisata }\end{array}$ & $\begin{array}{l}\text { Menampilkan kategori } \\
\text { dari tempat pariwisata } \\
\text { yang terdiri dari wisata } \\
\text { alam, religi, belanja, } \\
\text { kuliner, edukasi dan } \\
\text { budaya. }\end{array}$ \\
\hline 2 & $\begin{array}{l}\text { Foto } 360^{\circ} \\
\text { Tempat } \\
\text { Pariwisata }\end{array}$ & $\begin{array}{l}\text { Menampilkan foto 360 } \\
\text { tempat pariwisata }\end{array}$ \\
\hline 3 & $\begin{array}{l}\text { Lokasi } \\
\text { Pariwisata }\end{array}$ & $\begin{array}{l}\text { Menampilkan alamat } \\
\text { tempat pariwisata }\end{array}$ \\
\hline 4 & Exit & Keluar dari aplikasi \\
\hline
\end{tabular}

\section{b. Activity Diagram}

Activity diagram berfungsi untuk memodelkan aktifitas yang terjadi dalam sistem atau menggambarkan tingkah laku dinamis dari sebuah sistem. Pada Gambar 3 User dapat membuka aplikasi, memilih objek pariwisata dan memilih deskripsi lokasi pariwisata. Sistem akan menampilkan kategori tempat pariwisata, menampilkan foto tempat pariwisata dalam bentuk $360^{\circ}$.

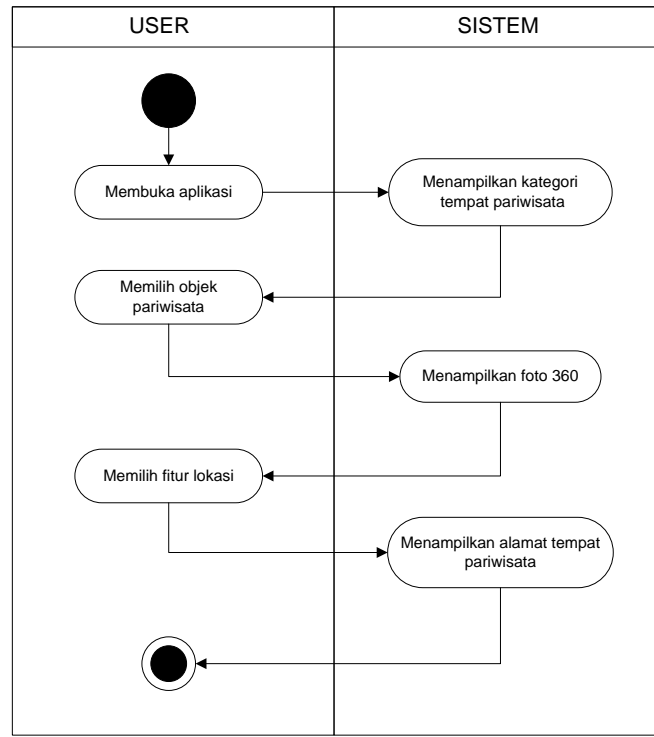

Gambar 3. Activity Diagram 


\section{c. Struktur Menu}

Struktur menu dalam aplikasi yang dirancang terdiri dari menu kategori tempat pariwisata dan menu exit. Di dalam menu kategori terdapat isi yang terdiri dari data pariwisata berupa foto $360^{\circ}$, deskripsi singkat lokasi tempat pariwisata.

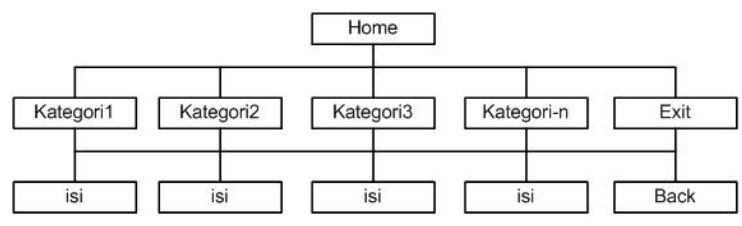

Gambar 4. Struktur Menu

\section{Penerapan Foto $360^{\circ}$ pada Unity 3D}

Penerapan Foto $360^{\circ}$ pada Unity 3D dilakukan dalam proses pembangunan aplikasi. Unity3D Engine merupakan suatu perangkat pengembangan game yang memiliki kualitas render serta cara kerja yang baik, menjadikannya sebagai perangkat yang intuitif dalam pembuatan 2D maupun 3D, memiliki kemampuan ketersediaan dalam berbagai platform serta

Assets dan komunitas yang sudah terkenal di penjuru dunia. Unity merupakan suatu game development ecosystem yang mampu diterapkan pada berbagai macam platform baik console, web, desktop dan mobile. Bahasa pemrograman utama Unity adalah C\# dengan IDE Mono Develop. Unity juga menyediakan berbagai pilihan bahasa pemrograman untuk mengembangkan game, antara lain JavaScript [9][10]. Foto $360^{\circ}$ diimport ke dalam aplikasi dimana nantinya akan masuk ke dalam asset yang ada pada project Unity.

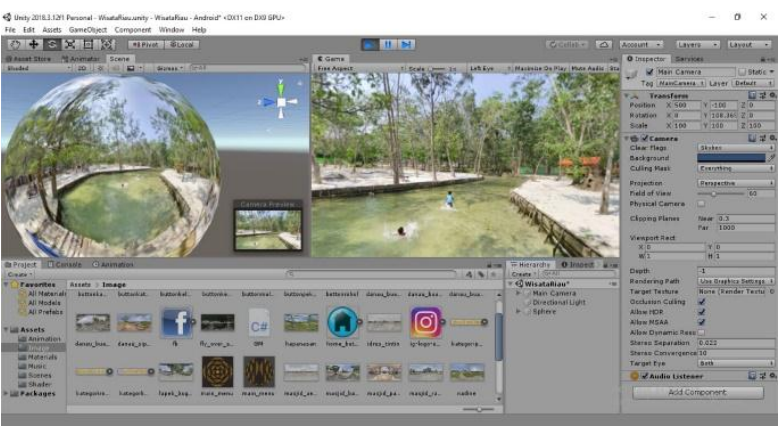

Gambar 5. Tampilan Penerapan foto $360^{\circ}$ pada Unity 3D

\section{HASIL DAN PEMBAHASAN}

Implementasi sistem dilakukan setelah proses perancangan dan kodingan selesai. Dimana didalam implementasi ini sistem dijalankan dan diamati untuk melihat kinerja yang dimilikinya. Berikut adalah implementasi untuk setiap proses yang ada pada sistem:

a. Tampilan Menu Utama

Setelah sistem dianalisis dan dirancang secara rinci, maka tahapan selanjutnya adalah implementasi. Implementasi sistem merupakan tahap meletakkan sistem sehingga siap untuk dioperasikan. Implementasi bertujuan untuk mengkorfimasi modul-modul perancangan, sehingga pengguna dapat memberi masukan kepada pengembang sistem.

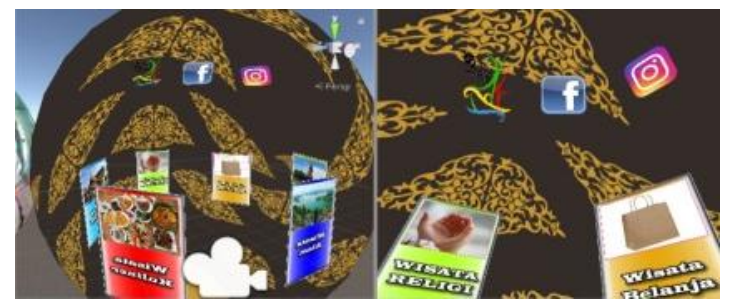

Gambar 6. Tampilan Menu Utama

b. Tampilan Foto $360^{\circ}$ Tempat Pariwisata Untuk melihat hasil atau menggunakan aplikasi dibutuhkan sebuah alat yaitu Google Cardboard. Google Cardboard merupakan alat virtual reality yang menggunakan smartphone sebagai platform/layar. Google Cardboard ditujukan agar pengguna smartphones dapat merasakan Virtual Reality dengan cara yang mudah. Google Cardboard dapat digunakan pada ponsel Android 4.1 (Jelly Bean) atau versi di atasnya. Layar handphone yang digunakan yaitu antara 4.5" s/d 6". Untuk layar yang ideal adalah 5.5" dengan resolusi Full HD, lebih baik lagi jika Quad HD [5].

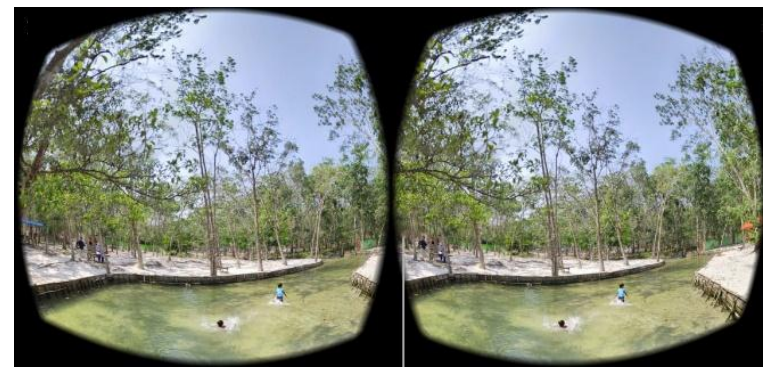

Gambar 7. Hasil Tampilan Foto $360^{\circ}$ 


\section{Pengujian}

Dalam pembuatan perangkat lunak, tahap pengujian merupakan hal yang penting dalam menentukan tingkat kebenaran perangkat lunak yang dibangun .

\section{a. Pengujian Black Box}

Black Box Testing berfokus pada spesifikasi fungsional dari perangkat lunak. Tester dapat mendefinisikan kumpulan kondisi input dan melakukan pengetesan pada spesifikasi fungsional program. Berdasarkan pengujian yang sudah di lakukan aplikasi dapat berjalan dengan baik, semua input dan output dapat berjalan sesuai hasil yang diharapkan.

Tabel 3. Black Box Testing

\begin{tabular}{|c|l|l|c|}
\hline No & \multicolumn{1}{|c|}{ Input } & \multicolumn{1}{|c|}{ Output } & Ket \\
\hline 1 & $\begin{array}{l}\text { User } \\
\text { menekan } \\
\text { tombol } \\
\text { mulai }\end{array}$ & $\begin{array}{l}\text { Menampilkan } \\
\text { tombol kategori } \\
\text { tempat } \\
\text { pariwisata }\end{array}$ & Berhasil \\
\hline 2 & $\begin{array}{l}\text { User } \\
\text { menekan } \\
\text { tombol } \\
\text { kategori }\end{array}$ & $\begin{array}{l}\text { Menampilkan } \\
\text { list pilihan } \\
\text { objek tempat } \\
\text { pariwisata }\end{array}$ & Berhasil \\
\hline 3 & $\begin{array}{l}\text { User } \\
\text { memilih } \\
\text { tempat } \\
\text { pariwisata }\end{array}$ & $\begin{array}{l}\text { Menampilkan } \\
\text { foto 360 } \\
\text { derajat dari } \\
\text { tempat } \\
\text { pariwisata }\end{array}$ & Berhasil \\
\hline 4 & $\begin{array}{l}\text { User } \\
\text { memilih } \\
\text { lokasi } \\
\text { tempat } \\
\text { pariwisata }\end{array}$ & $\begin{array}{l}\text { Menampilkan } \\
\text { alamat lokasi } \\
\text { tempat } \\
\text { pariwisata }\end{array}$ & Berhasil \\
\hline 5 & $\begin{array}{l}\text { User } \\
\text { menekan } \\
\text { tombol } \\
\text { kembali }\end{array}$ & $\begin{array}{l}\text { Kembali ke } \\
\text { halaman } \\
\text { sebelumnya }\end{array}$ & Berhasil \\
\hline 6 & $\begin{array}{l}\text { User } \\
\text { menekan } \\
\text { tombol } \\
\text { keluar }\end{array}$ & $\begin{array}{l}\text { Keluar dari } \\
\text { aplikasi }\end{array}$ & Berhasil \\
\hline
\end{tabular}

\section{KESIMPULAN}

Berdasarkan hasil perancangan dan implementasi sistem virtual tour reality, maka dapat diperoleh beberapa kesimpulan yaitu :

1. Telah dibangun sebuah aplikasi virtual tour reality promosi pariwisata di propinsi Riau.

2. Berdasarkan hasil pengujian black box didapat semua fungsi aplikasi berjalan dengan baik.

3. Aplikasi Virtual Tour Reality diharapkan dapat meningkatkan minat calon wisatawan untuk berkunjung dan meningkatkan potensi pariwisata di Riau khususnya Kota Pekanbaru.

\section{DAFTAR PUSTAKA}

[1]Nasuha Nasution, 2018. Sektor Pariwisata Jadi Primadona Baru di Riau dengan Tangan Dingin Gubernur Sektor Pariwisata Jadi Primadona Baru di Riau dengan Tangan Dingin Gubernur[Online](Updated 28 Januari 2018)

Available at:

https://pekanbaru.tribunnews.com/2018/01/28

/sektor-pariwisata-jadi-primadona-baru-diriau-dengan-tangan-dingin-gubernur?page=all [Accessed 15 April 2018]

[2] Ni Made Ary Widiastini. Nyoman Dini Andiani. Trianasari. Strategi Pemasaran Pariwisata Di Kabupaten Buleleng, Bali. Jurnal Ilmu Sosial dan Humaniora. 2012; Vol. 1, No. 1 : Halaman. 11.

[3] Osman A, N. A. Wahab, \& M. H. Ismail. 2009. Development and Evaluation of an Interactive $360^{\circ}$ Virtual tour for Tourist Destinations, Journal of Information Technology Impact.

[4]Nata, G. N. M. (2017). Aplikasi Virtual Tour Guide Sebagai Promosi Pariwisata Bali. Jurnal Sistem Dan Informatika (JSI), 11(2), 73-79.

[5] Waraney Sumayku P. F. Waraney, Virginia Tulenan, Alicia A. E. Sinsuw. Pengembangan Virtual Tour Potensi Wisata Baru Di Sulawesi Utara menggunakan Teknologi Video $360^{\circ}$. E-Journal Teknik Informatika Vol 12, No 1.

[6]S. J. Mcgriff, "Instructional System Design ( ISD ): Using the ADDIE Model," Instr. Syst. Coll. Educ. Penn State Univ., p. 2, 2000.

[7] N. A. . Zin, W. S. Yue, and A. Jaafar, "Digital game-based learning (DGBL) model and development methodology for teaching 
history," WSEAS Trans. Comput., vol. 8, no. 2, pp. 322-333, 2009.

[8] Marziah Karch, 2019. What Is an Android Photo Sphere?[Online](Updated 1 Juli 2019) Available at:

https://www.lifewire.com/what-is-androidphoto-sphere-1616136 [Accessed 16 Agustus 2019]

[9] Unity, "Game engine, tools and multi platfrom," Unity, [Online]. Available: http://unity3d.com/unity. [Accessed 5 Mei 2018].

[10] Pramudita, D.A. 2015. Pengembangan Aplikasi Artopeng sebagai Media Pengenalan Topeng Adat di Museum Sonobudoyo dengan teknologi Augmented Reality berbasis Desktop. Universitas Negeri Yogyakarta. 